\title{
Mal-Estar e a Negatividade: Uma Introdução ao Pensamento de Marcuse
}

JOEL BIRMAN

\section{Marcuse faz Cem Anos}

Este número de Physis é dedicado à figura de Herbert Marcuse, que faria agora cem anos, caso ainda estivesse vivo. O centenário de nascimento de Marcuse é a razão de ser desta publicação, dada a importância desse autor não apenas para os campos da filosofia e das ciências sociais, mas também para o da psicanálise. É no entroncamento criativo entre essas diferentes séries discursivas que se pode melhor surpreender as suas contribuições para a reflexão crítica e a renovação conceitual das ditas ciências humanas.

Foi em função desta direção de pesquisa e de sua inquietação em compreender a sua atualidade marcada por implosões do ideário humanista, reveladas pelo totalitarismo nazista e pela burocratização da revolução socialista na União Soviética, que Marcuse teve um encontro decisivo com Adorno, Horkheimer e Benjamin. Desse encontro, forjado no Instituto de Investigação Social, constituiu-se a Escola de Frankfurt, que elaborou o que se convencionou denominar "teoria crítica".

Não obstante as diferenças desses autores para a produção da teoria crítica, não resta qualquer dúvida, no entanto, que o cenário polêmico da instituição que os reunia oferecia as condições de possibilidade para que cada um deles pudesse, de maneira singular, desenvolver a sua própria concepção da teoria crítica e forjar o seu próprio destino intelectual. Para todos, contudo, o que estava sempre em causa era o diálogo da filosofia com o campo das ciências humanas, para que se pudesse compreender devidamente as novas formas de alienação social forjadas na sociedade capitalista avançada. As diferentes escolhas teóricas assumidas posteriormente por esses autores, enfim, não apagaram jamais a chama crítica que se acendeu no início dos 
anos trinta, e que manteve incólume a espinha dorsal do dito projeto crítico então estabelecido.

Com isso, define-se a identidade intelectual de Marcuse e o seu oculto objeto de desejo, isto é, aquilo que impulsiona seu trabalho teórico e os embates em que se inseriu na cena contemporânea. Assim, não obstante a sua inserção no discurso filosófico, Marcuse circula num campo de reflexão e de polêmica interdisciplinar, que é uma das marcas de seu estilo de pensamento. Isso porque apenas assim seria possível um trabalho crítico sobre as formas modernas de alienação, para que se pudesse acender novamente o sonho da liberdade enquanto contraponto aos conformismos instituídos na sociedade industrial avançada.

Uma tensão interna perpassa permanentemente o pensamento de Marcuse, na medida em que este oscila entre uma tendência para o abstrato e uma outra que o impele fortemente para a análise das situações concretas. Atração fatal, sem dúvida, que tempera com os sabores acre-doces o que existiria de insosso nas abstrações do discurso filosófico. É este contraponto o que regula internamente o seu discurso teórico em seus menores detalhes, revelando, pois, as imantações que constituem o seu pensamento. Para nos aproximar da estrutura de seu pensamento, de sua forma de ser, nada mais eloqüente do que evocar sumariamente o seu percurso intelectual e acadêmico.

\section{Esboço de um Percurso}

Nascido em Berlim em 1898, Herbert Marcuse realizou seus estudos em Berlim e em Freiburg, onde se doutorou em 1925. Na Universidade de Freiburg, foi aluno de Husserl e de Heidegger; dois expoentes da filosofia alemã neste século. Como muitos de seus contemporâneos, Marcuse sofreu o impacto da publicação de Ser e tempo ${ }^{1}$, de Heidegger, em 1927. Como conseqüência, realizou sua tese de docência sob a orientação deste, na qual trabalhou sobre $\mathrm{Hegel}^{2}$. Empreendeu, então, a leitura dos fundamentos da teoria da historicidade em Hegel, tendo como base um estudo crítico sobre a ontologia deste. Seu interesse pelas questões concretas colocadas pelo

Heidegger, M. Etre et temps. Paris: Gallimard, 1986 [1927].

2 Marcuse, H. Hegel's ontology and the theory of historicity. Cambridge, London: The MIT Press. 1987 [1932]. 
socialismo em construção, assim como sua pesquisa sobre Hegel, conduziram Marcuse, inevitavelmente, para o estudo de Karl Marx.

Não obstante as irrefutáveis marcas heideggerianas de seu pensamento, as posições políticas de Heidegger distanciaram provavelmente Marcuse deste $^{3}$. O engajamento de Heidegger com o nacional-socialismo tornou a ruptura inevitável. Contudo, Marcuse leu Heidegger à sua maneira, incorporando as teses deste na direção de sua pesquisa, de forma inventiva. Assim, ao assinalar a leitura do sujeito como um ser-no-mundo (Dasein), de acordo com a proposição de Heidegger, Marcuse pontuou esse enunciado filosófico numa direção oposta à da voz do ser, já que como ser-no-mundo a subjetividade deveria ser inscrita na realidade social enquanto tal. Com isso, infletiu o filosofema de Heidegger numa direção inédita, de maneira a articulá-lo com as suas leituras anteriores de Hegel e Marx. Foi em função dessa escolha teórica que Marcuse foi para Frankfurt, pela indicação de Husserl, para trabalhar no Instituto de Pesquisa Social.

Contudo, com a ascensão do nazismo Marcuse emigrou para os Estados Unidos, em 1934. Inicialmente, trabalhou no citado centro de pesquisa, associado então com a Universidade de Colúmbia. Em seguida, se inseriu no Departamento de Estudos Estratégicos e no Departamento de Estado, entre 1941 e 1950, trabalhando no campo da política. Porém, de 1951 a 1953 foi professor do Instituto Russo, nas Universidades de Colúmbia e de Harvard. Entre 1954 e 1965, foi professor da Universidade de Brandies, em Boston. Finalmente, foi professor da Universidade da Califórnia, a partir de 1965. Em 1967, seu pensamento foi um referencial crucial na Alemanha, na qual circulava entre os grupos de esquerda e os estudantes revolucionários que promoviam as revoltas que subverteram toda a Europa. Os movimentos estudantis de 1967 e 1968, que balançaram a Europa, os Estados Unidos e a América Latina, colocaram o pensamento de Marcuse no primeiro plano da cena revolucionária. Foi então transformado em herói dos novos tempos de tormenta com as barricadas parisienses de maio de 1968.

\section{Trabalho do Negativo, Mobilidade e Vir-a-Ser}

Procurando inscrever agora este percurso formal no campo substantivo de sua produção teórica, pode-se depreender que foi na inflexão para a realidade social que Herbert Marcuse interpretou a condição humana de

3 Ferrater Mora, J. Diccionario de Filosofia. Madrid: Alianza Editorial, 1982, p. 2.105, v. 3. 
ser-no-mundo, proposta na filosofia de Heidegger. Por esse viés teórico Marcuse pôde empreender a sua leitura crítica de Hegel, dando o devido destaque para a categoria de negatividade, para a compreensão da dialética hegeliana. Seria no trabalho do negativo que se poderia captar a grande contribuição teórica daquele para a filosofia. Contudo, Hegel foi infiel ao trabalho inventivo da negatividade que tinha proposto, ao realizar o fechamento do seu sistema no suposto espírito absoluto e obturar, assim, a mobilidade da razão dialética.

Com isso, Marcuse formula que a história é uma questão de vir-a-ser ${ }^{4}$, não sendo, pois, algo substantivamente dado, mas um projeto que é permanentemente relançado e recomeçado. Pode-se entrever, por esse viés, a linha que articula todo o projeto teórico de Marcuse desde os seus primórdios, centrado na problemática da mobilidade. Evitar o confronto com esta, é permanecer inerte e conformado. Assumi-la, em contrapartida, implica realizar a paciência do trabalho do negativo, que estaria em vias de desaparecer. Para isso, é preciso romper com as imposturas que se apresentam como filosofia positiva, que legitimam a resignação, e que tratam as leis da sociedade como se fossem as leis da natureza. Esquece-se, com esse conformismo, que a história implica ações e escolhas dos homens. Por isso, este é um vir-a-ser, o que define a mobilidade e o trabalho da negatividade. Enfim, pensar a história como vir-a-ser, onde se cadencia a operação do negativo, é se contrapor decididamente à condição de servidão do sujeito e ao seu conformismo.

Por essa perspectiva de leitura da dialética Marcuse encontrou-se com Marx, na crítica empreendida por este de qualquer sociedade de classe como sendo um obstáculo para o encontro do sujeito com a sua liberdade. Isso porque o fechamento da dialética hegeliana conduziria não apenas ao realismo da razão, mas também ao positivismo e ao servilismo. Em contrapartida, o trabalho do negativo indicaria os caminhos da emancipação, pelo descortino da utopia no horizonte do pensamento e da ação. Nesta perspectiva, Marcuse encontrou-se, inevitavelmente, com as linhas de pesquisa do Instituto de Investigação Social. Nesse contexto, elaborou uma série de ensaios sobre sociedade e cultura ${ }^{5}$, que interviram diretamente nos debates teóricos dos anos trinta. Além disso, empreendeu logo em seguida, em 1938, uma interpretação do totalitarismo nazista, com a obra Razão e revolução $o^{6}$. Finalmente,

\footnotetext{
Marcuse, H. Hegel's ontology and the theory of historicity. Op. cit.

Marcuse, H. Culture et société. Paris: Editions de Minuit, 1970.

6 Marcuse, H. Raison et révolution. Paris: Editions de Minuit, 1968 [1938].
} 
seguindo uma linha próxima de trabalho, publicou o livro $O$ marxismo soviético ${ }^{7}$, em 1958, no qual realizou a crítica das formas burocráticas assumidas pelo socialismo, pondo o dedo nos descaminhos deste.

Numa outra direção de pesquisa, complementar à anterior, Marcuse procurou explorar a categoria de trabalho e o trabalho do negativo do pensamento na interpretação de Freud. Como decorrência, publicou Eros e civilização ${ }^{8}$, em 1955, no qual procurou articular as dimensões do prazer e do trabalho na sociedade industrial avançada. Para isso, procura aproximar e costurar os discursos de Freud e de Marx, com o intuito de realizar a crítica das formas contemporâneas de alienação. Começa a indicar com essa modalidade de leitura de que maneira o conformismo convive com a tolerância política existente nas sociedades industriais avançadas. Seria, pois, pelo viés da construção da subjetividade que Marcuse procurou compreender a falência do trabalho do negativo no capitalismo avançado.

Como desdobramento dessa indagação teórica, Marcuse procurou compreender a construção do "homem unidimensional", destituída que seria então a subjetividade do poder da crítica e da liberdade na sociedade industrial dos anos sessenta ${ }^{9}$. Com isso, inicia a crítica sistemática de certas formações discursivas que nos são ainda atuais, tais como a filosofia analítica e o pragmatismo. Essas formações indicariam os descaminhos da razão crítica em pleno mundo da tolerância, no qual o conformismo e a servidão voluntária seriam as suas resultantes fundamentais. Neste particular, Marcuse continua coerente com os pressupostos teóricos estabelecidos na sua leitura de Hegel, em que a mobilidade dialética e o trabalho do negativo definiriam a condição da historicidade como vir-a-ser, sendo, pois, a condição da própria liberdade. Nestes termos, Marcuse continua sendo de uma enorme atualidade , não apenas porque o conformismo e a servidão voluntária são os atores da dita cena pós-moderna, mas também porque se encontra com os autores dos dias de hoje que buscam pensar a história como vir-a-ser, tais como Badiou, Rancière e Agamben ${ }^{10}$.

No que concerne a isso, aliás, Marcuse apostava decididamente no potencial revolucionário dos grupos e segmentos sociais minoritários em oposição à

\footnotetext{
7 Marcuse, H. Le marxisme soviétique. Paris: Gallimard, 1963 [1958].

8 Marcuse, H. Eros e civilização. Rio de Janeiro: Editora Zahar, 1973 [1955].

- Marcuse, H. L'homme unidimensionnel. Paris: Editions de Minuit, 1968.

${ }^{10}$ Châtelet, G. Relire Marcuse pour ne pas vivre comme des porcs. Le monde diplomatique. Paris, n. 533 , p. 22-23, ago. 1998.
} 
classe operária, na medida em que esta se inscrevia nas crenças do sistema social instituído; tendo perdido, pois, o seu potencial crítico no universo marcado pela tolerância. Aqueles outros grupos sociais seriam ainda permeados pelo cheiro da liberdade e pelo desejo de subverter a ordem, justamente porque estariam à margem do sistema e poderiam realizar o trabalho do negativo. Pode-se depreender que ainda é necessário reler Marcuse para "não se viver como porcos", de acordo com a forte expressão de G. Châtelet ${ }^{11}$, na medida em que seu trabalho procurou ferir de morte o conformismo e a servidão na sociedade da tolerância, pela evocação permanente do trabalho do negativo e do homem como vir-a-ser. Silenciar esta dimensão fundamental da condição humana seria apagar o que nos distingue do reino da natureza, isto é, a nossa liberdade.

\section{Mal-Estar, Emancipação e Utopia}

É possível reconhecer no percurso teórico de Herbert Marcuse, agora do estrito ponto de vista metodológico, que pela leitura da realidade social e das situações exemplares do mundo contemporâneo esse autor realizou uma leitura interdisciplinar da sociedade capitalista avançada, não obstante a sua inserção primordial no discurso filosófico. Se isso por si só já justifica um número dedicado ao seu pensamento numa revista de Saúde Coletiva, na medida em que Marcuse trabalhou com problemáticas caras deste campo, é preciso indicar, ainda, a pertinência disso numa outra direção. É preciso ficar atento, também, para as particularidades das problemáticas que foram desenvolvidas na pesquisa de Marcuse, já que essas especificidades indicam bem de perto o campo atual da Saúde Coletiva. Vale dizer, Marcuse trabalhou com questōes que diretamente interessam a esse campo, como pretendo assinalar, agora, de forma esquemática.

A maneira pela qual Marcuse procurou repensar nas novas modalidades de relações sociais de trabalho na aurora dos anos cinqüenta, que ainda nos interessa para pensar nas relações dos indivíduos com o corpo e com os instrumentos de trabalho, é uma evidência da incidência de sua pesquisa no campo da Saúde Coletiva. Além disso, como esta reflexão se desdobra numa outra sobre o estatuto da subjetividade nas novas condições sociais, nas quais se transformam as relações do trabalho com o prazer, é um outro

"Idem. 
exemplo desta importância. As formas pelas quais o sistema do capitalismo avançado produz novas modalidades de alienação caracterizada pela unidimensionalidade do humano, é um outro tópico que revela o interesse de Marcuse para o campo da Saúde Coletiva. Sua leitura do socialismo e do marxismo soviéticos, na qual a análise que realizou das formas assumidas pela burocracia teve um evidente sabor antecipatório dos acontecimentos que assistimos nos últimos anos. Finalmente, sua interpretação sobre o nazismo é de grande atualidade, dado o retorno deste, nas práticas sociais contemporâneas, de maneira assustadora.

Evidencia-se, assim, que na obra de Marcuse a problemática do mal-estar na sociedade industrial avançada ocupa uma posição estratégica. Não há qualquer dúvida no que concerne a isso, na medida em que é o mal-estar que indica o que deve ser investigado, circunscrevendo numa dada realidade social o que se apresenta como questão. $O$ mal-estar funciona como uma bússola, delineando as rotas e as trilhas para o trabalho de invenção teórica. Isso porque o mal-estar é o indicador mais seguro de que algo da ordem do negativo se processa no real, e que o vir-a-ser, como mobilidade, se indica como signo.

Marcuse segue, dessa maneira, e sempre, as trilhas e as pegadas do malestar. Com a problemática do mal-estar, Marcuse está permanentemente confrontado numa verdadeira justa, num combate de gigantes, para delinear não apenas outras maneiras de pensar o mal-estar, mas também para sugerir alternativas possíveis, decorrentes da própria reflexão crítica e do trabalho da negatividade. Porque o ideal emancipatório é o que regula a pesquisa de Marcuse. A emancipação humana é a finalidade sempre presente em sua reflexão crítica, na medida em que a liberdade é a marca fundamental do humano. Disso decorre a dimensão utópica que é o traço insofismável de seu pensamento. A presença da utopia em Marcuse foi reconhecida por diferentes autores que debateram sua obra, e que se alimentaram de diferentes maneiras de suas intuições teóricas ${ }^{12}$.

\section{Entre Ciências Sociais, Psicanálise e Filosofia}

Pode-se reconhecer a atualidade de Marcuse não apenas pela dimensão interdisciplinar de sua investigação, mas também pela especificidade de seus

12 Raulet, G. Herbert Marcuse, philosophie de l'émancipation. Paris: PUF, 1992. 
temas. Além disso, ambas as dimensões de seu trabalho interessam bastante às linhas de pesquisa presentes, hoje, no campo da Saúde Coletiva. Daí porque se justifica que Physis dedique todo um número ao seu percurso.

A organização editorial da publicação procurou dividir o espaço disponível dando ênfase às diferentes direções de trabalho de Marcuse que margeiam o campo da Saúde Coletiva. Num dos pólos, demos prioridade à política e às ciências sociais, enquanto no outro encontram-se as contribuiçōes da psicanálise. Entre esses pólos, o discurso filosófico de Marcuse está sempre presente, permeando as diferentes dimensões de sua teoria crítica. Para sublinhar a atualidade e a pertinência das problemáticas desenvolvidas por Marcuse, inserimos, neste número de Physis, contribuiçōes para a leitura do mal-estar na modernidade. Nessas, o discurso psicanalítico se revela como um instrumento crucial para a construção da teoria crítica, permitindo a compreensão do conformismo que marca a nossa contemporaneidade. Isso porque acreditamos que celebrar um autor e honrar assim o seu percurso intelectual implica não apenas evocar suas teorias e criticá-las devidamente, mas também recolocar em cena os destinos atuais das problemáticas que Marcuse trabalhou.

Como complemento, inserimos, também, uma das primeiras elaborações teóricas da categoria de saúde no campo das ciências sociais, empreendida por Aubrey Lewis, por diferentes razões. Antes de mais nada, pela sua evidente importância histórica. Introduzimos, portanto, um texto clássico, para as ciências sociais e para a Saúde Coletiva, em língua portuguesa, esperando contribuir para o enriquecimento bibliográfico e o trabalho de pesquisa no Brasil. Esse ensaio inaugural sobre a categoria de saúde na sociologia foi produzido no momento histórico em que Marcuse escrevia as suas grandes obras; sendo, pois, autores contemporâneos. Finalmente, porque a elaboração da categoria de saúde reenvia para a problemática do mal-estar no social, que está no centro desta publicação.

Rio de Janeiro, 2 de outubro de 1998. 